\title{
Potential Application of Membrane Capacitive Deionization for Heavy Metal Removal from Water: A Mini-Review
}

\author{
Jialin Yang ${ }^{1,2}, Y_{\text {a Bu }}^{1,2}$, Fangyuan Liu ${ }^{1,2}$, Wenqing Zhang ${ }^{1,3}$, Dandi Cai ${ }^{1,2}$, Aodi Sun ${ }^{1,2}$, Yuqi Wu ${ }^{1,2}$, \\ Rui Zhou ${ }^{1,2, *}$, Chunpeng Zhang ${ }^{1,2,3, *}$ \\ ${ }^{1}$ Key Laboratory of Groundwater Resources and Environment (Ministry of Education), Jilin \\ University, Changchun 130021, China. \\ ${ }^{2}$ National and Local Joint Engineering Laboratory for Petrochemical Contaminated Site Control and \\ Remediation Technology, Jilin University, Changchun 130021, China. \\ ${ }^{3}$ Jilin Provincial Key Laboratory of Water Resources and Environment, Jilin University, Changchun \\ 130021, China. \\ (Jialin Yang and Ya Bu contributed equally to this review) \\ *E-mail: zhang_cp@jlu.edu.cn, zhour@jlu.edu.cn
}

doi: $10.20964 / 2020.08 .98$

Received: 11 May 2020 / Accepted: 10 June 2020 / Published: 10 July 2020

\begin{abstract}
Heavy metal pollution of the aquatic environment has become a global concern in recent decades, and conventional methods for heavy metal removal, like coagulation, precipitation, and membrane filtration, have their limitations. In this mini-review, we discuss four aspects of heavy metal removal by membrane capacitive deionization (MCDI): i) the role of electrode materials; ii) role of ion-exchange membrane; iii) operating conditions; and iv) water chemistry. Based on this discussion, we determine MCDI to have good potential for heavy metal removal in water. Future MCDI studies should focus on synthesizing ionselective electrode to promote the removal of specific ionic species; developing multifunctional electrodes for the simultaneous removal of different heavy metals; performing pilot-scale studies instead of bench-scale ones; applying MCDI to raw water or real-life water samples and controlling MCDI with different current modes.
\end{abstract}

Keywords: capacitive deionization; heavy metal; arsenic; cadmium; pulsed current

\section{FULL TEXT}

(C) 2020 The Authors. Published by ESG (www.electrochemsci.org). This article is an open access article distributed under the terms and conditions of the Creative Commons Attribution license (http://creativecommons.org/licenses/by/4.0/). 